\title{
ENCEPHALOPATHIES
}

\section{PORPHYRIA PRESENTING AS DIFFUSE ENCEPHALOPATHY}

An 18-year-old female presenting with seizures, myalgias, abdominal pain, headache and vomiting had multiple large contrast-enhancing white matter lesions on MRI and was diagnosed with acute intermittent porphyria (AIP), in a report from the Department of Neurology, Mayo Clinic, Rochester, MN. She was febrile, confused, complained of visual hallucinations, and had increased blood pressure and tachycardia. Liver enzymes were elevated and electrolytes lowered. AIP was considered because of seizures, dysautonomia, and abdominal pain. Uroporphyrin levels were $2,186 \mathrm{mcg} / 24 \mathrm{hrs}$ (normal, 3-25), and porphobilinogen, $312.8 \mathrm{mg} / 24 \mathrm{hrs}$ (normal, 0-0.5). Urine was dark, resembling ale or tea. Fecal porphyrin profile excluded hereditary coproporphyria and variegate porphyria. One week after treatment with IV hematin and dextrose, MRI lesions resolved. (Maramattom BV, Zaldivar RA, Glynn SM et al. Acute intermittent porphyria presenting as a diffuse encephalopathy. Ann Neurol April 2005;57:581-584). (Respond: Dr Wijdicks, Mayo Clinic College of Medicine, Department of Neurology, W8B, 200 First Street SW, Rochester, MN 55905).

COMMENT. AIP is an autosomal dominant disorder caused by a genetic deficiency of PBG deaminase enzyme involved in heme synthesis. Most patients are asymptomatic, but under stress, during menstruation, surgery, fasting or exposure to drugs, an acute attack may occur, with heme precursors, aminolevulinic acid and PBG, excreted in the urine. Treatment with barbiturates will aggravate or precipitate an attack. Episodes present with abdominal pain, vomiting, seizures, neuropathy, dysautonomia, and psychiatric symptoms. Encephalopathy, a presenting symptom in the above case, is unusual, but combined with abdominal pain, should arouse suspicion of AIP. A more common variety of porphyria in childhood is congenital erythropoietic porphyria, presenting with cutaneous photosensitivity and hemolytic anemia, but no neurologic symptoms.

\section{CYSTIC LEUKOENCEPHALOPATHY WITH NORMOCEPHALY}

A new syndrome of nonprogressive encephalopathy with normo- or microcephaly and early onset of psychomotor impairment is described in 15 children, in a report from the University of Gottingen and other centers in Europe and the US. Clinical findings include patients of Turkish origin; consanguinity of parents in $5 ; 2$ patients siblings and 2 first cousins; age at onset birth to 18 months; microcephaly in 9 and normocephaly in 6; impaired motor and mental development; epilepsy in 8 ; spasticity in 12; hearing impairment in 5; normal peripheral nerves; course stable or slowly progressive. Tests for metabolic and infectious disease were negative. MRI findings included supratentorial white matter lesions with a high signal on T2 weighted images involving mainly periventricular regions, sparing of central white matter and cerebellar white matter, cystic lesions in anterotemporal lobes not connected to the ventricles, pericystic abnormal myelination on FLAIR-weighted images, enlarged temporal horn, and no involvement of gray matter. The cause is unknown, but an autosomal recessive inheritance is suspected and is under investigation. (Henneke M, Preuss 